\title{
Target Area Design Issues for Implementing Direct Drive on the National Ignition Facility
}

M. Tobin, V. Karpenko,

A. Burnham, and R. Peterson
RECENED

AUG 161996

O.S.TI

This paper was prepared for submittal to the American Nuclear Society 12th Topical Meeting on the Technology of Fusion Energy

Reno, NV

June 16-20, 1996

June 14, 1996

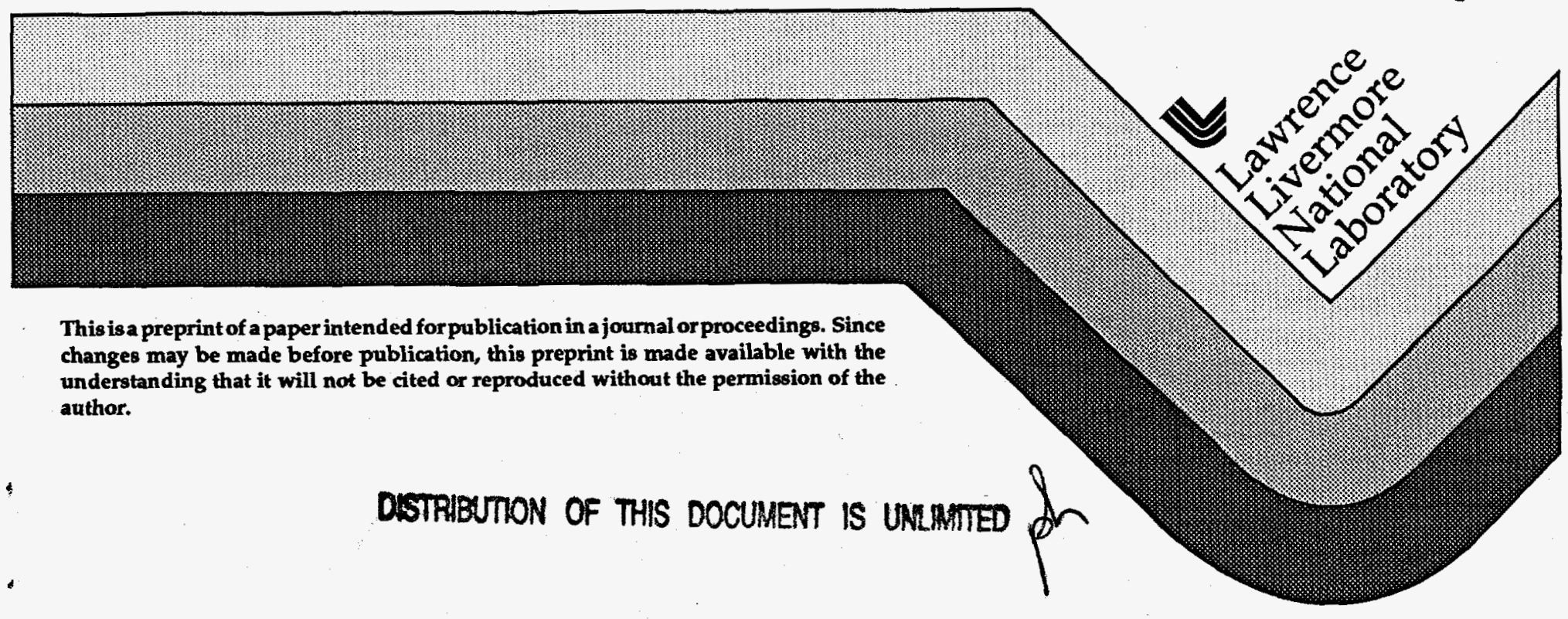




\section{DISCL.AIMER}

This document was prepared as an account of work sponsored by an agency of the United States Government. Neither the United States Government nor the University of California nor any of their employees, makes any warranty, express or implied, or assumes any legal liability or responsibility for the accuracy, completeness, or usefulness of any information, apparatus, product, or process disclosed, or represents that its use would not infringe privately owned rights. Reference herein to any specific commercial product, process, or service by trade name, trademark, manufacturer, or otherwise, does not necessarily constitute or imply its endorsement, recommendation, or favoring by the United States Government or the University of California. The views and opinions of authors expressed herein do not necessarily state or reflect those of the United States Government or the University of California, and shall not be used for advertising or product endorsement purposes. 


\section{DISCLAIMER}

Portions of this document may be illegible in electronic image products. Images are produced from the best available original document. 


\title{
TARGET AREA DESIGN ISSUES FOR IMPLEMENTING DIRECT DRIVE ON THE NATIONAL IGNITION FACILITY
}

\author{
M. Tobin, V. Karpenko, A. Burnham \\ Lawrence Livermore National Laboratory \\ P.O. Box 808, L-481 \\ Livermore, CA 94550 (510/423-1168) \\ R. Peterson \\ Fusion Technology Institute \\ University of Wisconsin \\ 1500 Engineering Drive \\ Madison, WI 53706 (608/263-5646)
}

\section{ABSTRACT}

The National Ignition Facility (NIF) will be configured in its baseline design to achieve ignition and gain using the indirect drive approach. However, the NIF primary criteria and functional requirements require the NIF design "to not preclude" the ability to conduct inertial confinement fusion experiments using the direct drive approach.

The direct drive approach requires symmetrical illumination of an inertial confinement fusion (ICF) capsule where each beam fully subtends the capsule. Therefore, the re-directing of 24 of the $48 \mathrm{NIF}$ beamlines (each consisting of a $2 \times 2$ beamlet group) from $\sim 30^{\circ}$ and $-50^{\circ}$ cone angles to $\sim 75^{\circ}$ cone angles located near the chamber 'equator' is required. This would be accomplished by adjusting intermediate transport mirrors such that the beams would intercept different final mirrors in the Target Bay and be directed into final optics assemblies attached to chamber ports positioned at the new port locations. Allowing space to be able to convert from one irradiation scheme to another while fully meeting the mechanical stability requirements for each approach is a significant challenge. Additionally, NIF user needs (features supporting weapons physics, weapons effects, inertial fusion energy, or Basic Energy Sciences) cannot be compromised by direct drive needs.

The target for direct drive, absent a hohlraum, emits much fewer cold $x$ rays than in the indirect drive case. Further, the irradiation scheme, by its nature, may not result in the absorption of all of the $3 \omega$ light and therefore could create a unique hazard to the NIF chamber first wall of significant fluences of scattered UV laser light. This paper describes possible design features of the NIF Target Area to allow conversion to a direct drive capability, and discusses some of the differences in post-shot conditions created compared to indirect drive.

\section{INTRODUCTION}

The NIF will consist of a $1.8-\mathrm{MJ}, 0.35-\mu \mathrm{m}$ laser with 192 independent beamlets. This represents an approximately 50-fold increase in laser energy and $~ 15$-fold increase in power over the Nova facility located at Lawrence Livermore National Laboratory (LLNL). The main pulse length will be $\sim-4 \mathrm{~ns}$. Beams are transported into the chamber in groups of $4(2 \times 2)$ and further in four cones, with two cones of $\sim 27^{\circ}$ and $\sim 53^{\circ}$ oriented around each pole of the sphere. Target experiments will be positioned from a horizontally-placed target inserter in a 5-m radius, 10-cm thick Al sphere. Diagnostics, mostly based in diagnostic manipulators, are mainly positioned around the mid-plane of the chamber.

Research at the University of Rochester Laboratory for Laser Energetics, LLNL, and elsewhere suggests ignition and gain for direct drive may be possible at laser energies at or below that projected for the NIF. ${ }^{1}$ Although considered possibly higher risk due to the potential for Raleigh-Taylor instabilities disrupting capsule performance, the scientific benefits of being able to explore direct drive physics on the NIF are compelling and led to the decision to include the possibility of conducting such experiments.

To achieve direct drive, 24 of the $482 \times 2$ beamlines must be re-directed to near the mid-plane of the chamber. This is accomplished by placing additional turning mirrors in the Target Bay for selected beamlines that are utilized only when switching from one mode to another. Increased laser bandwidth is achieved by adjustments in the Master Oscillator Room. This may require an additional KDP crystal be inserted into the conversion array, causing a redesign of the conversion scheme. The kino-form phase plate used for indirect drive is replaced by a different diffractive grating that achieves the required 2-D random phase distribution in the beam. Twenty-four final optics assemblies are either re-positioned from their indirect drive 
locations or added to the new direct drive locations. Laser light absorbers that absorb unconverted light on the chamber interior wall are moved, or new ones are added to manage the unconverted light emitted from the 'new' direct drive ports.

Differences in the post shot environment from indirect drive include: the absence of cold $x$ rays, more severe first surface ion heating from target debris, a greater quantity of unburned tritium to evacuate per shot, a rapidly extracted target shroud, and a $\sim 0.3 \mathrm{~J} / \mathrm{cm}^{2}$ fluence of $3 \omega(0.35 \mu \mathrm{m})$ laser light on the first wall. The effects of these differences are discussed.

\section{BEAM REQUIREMENTS FOR DIRECT DRIVE}

Primary criteria and functional requirements for direct drive implementation on the NIF have been proposed. ${ }^{1}$ The laser pulse energy is $1.5 \mathrm{MJ}$, peak power is $450 \mathrm{TW}$, with a non-uniformity on target of $1 \%$. Main pulse laser bandwidth is $1-2 \mathrm{THz}$, beamlet spot size at chamber center is $1-4 \mathrm{~mm}$, and maximum pulse duration is $30 \mathrm{~ns}$. Speckle smoothness in the main pulse is $2 \%$ and would be accomplished by implementing 2-D SSD (smoothing by spectral dispersion).

\section{MECHANICAL LAYOUT DIFFERENCES FROM INDIRECT DRIVE}

In order to transport the 24 beamlines from entering as for indirect drive to entering near the 'waist' of the chamber for direct drive, eight of the beams require the addition of three transport mirrors. The net difference in beam path increases from $7.9 \mathrm{~m}$ to $22 \mathrm{~m}$. This has impacts on the front end of the laser, the pockels cells, and harmonic conversion systems. Table 1 below describes the specific beamline cone angle changes of indirect drive beams to direct drive beams that would be required to support direct drive on NIF. ${ }^{2}$

Table 1. Cone angles for Indirect Drive and Direct Drive Operations on NIF

\begin{tabular}{|c|c|c|c|}
\hline Cone & $\#$ Ports & Indirect Drive & Direct Drive \\
\hline 1 & 4 & $23.5^{\circ}$ & $23.5^{\circ}$ \\
\hline 2 & 4 & $30^{\circ}$ & \\
\hline 3 & 8 & $46.5^{\circ}$ & $46.5^{\circ}$ \\
\hline 4 & 8 & $50^{\circ}$ & \\
\hline 5 & 12 & & $74.85^{\circ}$ \\
\hline
\end{tabular}

It is possible to redirect each of the $242 \times 2$ bundles from indirect to direct drive by horizontally translating one mirror in the target bay. All existing transport mirrors assemblies are used to transport the beams and each $74.85^{\circ}$ direct drive beam will require an additional set of transport mirrors for a total of 96 additional mirrors. This layout is shown in Fig. 1. Interferences with the NIF baseline diagnostics placement have been resolved, as has the repositioning of the vacuum system from the target chamber waist to the chamber pedestal. Floor 'cut-outs' allow space for installing final optics assemblies (FOA) for direct drive.

The current indirect drive solution to managing unconverted light is to use fused-silica-covered standard absorbing glass mounted on the interior chamber wall, as on Nova. The direct drive implementation would require repositioning of the 24 'beam dumps' that have had their beams moved. Due to the larger spot size required for direct drive, $2-4 \mathrm{~mm}$ compared to $0.5 \mathrm{~mm}$ for indirect drive, the intensity modulations on the beam may be as high as $6: 1$ or more rather than the 3:1 expected for indirect drive, at the 'beam dump' location. 1 This may raise concerns about the survivability of the absorbers, which may be exposed to peak intensities $\geq 30 \mathrm{~J} / \mathrm{cm}^{2}$ in $2-3 \mu \mathrm{m}$ spots that cover a few percent of the area of the fused silica cover.

\section{FIELDING CRYOGENIC DIRECT DRIVE TARGETS}

Direct drive targets will contain up to $15 \mathrm{Ci}$ of tritium per target. The total allowed inventory of tritium in the NIF is $\leq 500 \mathrm{Ci}$. Of this, $75 \mathrm{Ci}$ has been allocated to targets sitting in target storage awaiting final fuel layering and insertion into the target chamber. Therefore, five direct drive targets can be in the NIF at one time. ${ }^{3}$ Placing the target inserter/positioner in the vertical position, like Omega Upgrade, presents unique challenges for the NIF design due to limited access to this area. The target shroud positioner will likely need to be positioned opposed to the target positioner and may present further interferences. Therefore, the intent is to place the inserter in the horizontal position or integrate it with the elevator/lift assembly at the bottom of the NIF chamber. Techniques used to implement cryogenic direct drive on Omega will likely be adapted as is possible for NIF.

\section{DIRECT DRIVE TARGET EMISSIONS}

The direct and indirect drive targets for the NIF have substantial differences in emissions and consequently produce different effects. The NIF indirect drive target has been described in detail elsewhere. ${ }^{4}$ It consists of a $\mathrm{He} / \mathrm{H}$ gas-filled cylindrical gold hohlraum surrounding a fuel capsule with a doped plastic or beryllium ablator. The direct drive target is a spherical shell of DT fuel with a thin plastic ablator. 5 
The emission of $x$ rays, neutrons, and debris by ICF targets play an important role in the design of the target chamber for NIF. The direct and indirect drive targets release rather different emissions. The calculated emissions are summarized in Table 2. Two variants of each target type were considered. The direct drive target is either pure DT or coated with a thin plastic shell. The plastic-coated version is of course more credible from a target fabrication and survival point of view; the pure DT case is presented only for comparison. Two indirect drive targets are also considered; one that just barely ignited and one with significant yield. The indirect drive targets are physically identical, but the lasers were not properly aligned inside the hohlraum in the 'barely ignited' target scenario. These calculations were performed by Peterson at Los Alamos National Laboratory (LANL) using the LASNEX computer code.

Table 2. ICF Direct- and Indirect Drive-Emitted Target Energy Balance Comparison

\begin{tabular}{|l|c|c|c|c|}
\hline & \multicolumn{2}{|l|}{ Direct Drive } & \multicolumn{2}{l|}{ Indirect Drive } \\
\hline $\begin{array}{l}\text { Energy } \\
\text { (MJ) }\end{array}$ & Pure DT & $\begin{array}{c}\text { CH- } \\
\text { Coated }\end{array}$ & $\begin{array}{c}\text { Just } \\
\text { Ignited }\end{array}$ & $\begin{array}{c}\text { Large } \\
\text { Yield }\end{array}$ \\
\hline Laser & 1.26 & 1.27 & 1.31 & 1.33 \\
\hline $\begin{array}{l}\text { Fusion } \\
\text { Yield }\end{array}$ & 38.6 & 39.7 & 0.11 & 9.4 \\
\hline Neutron & 32.4 & 33.1 & 0.08 & 7.1 \\
\hline X rays & 0.4 & 0.4 & 0.45 & 2.0 \\
\hline Debris & 7.04 & 7.44 & 0.89 & 1.63 \\
\hline Total & 39.8 & 41.0 & 1.42 & 10.73 \\
\hline
\end{tabular}

The two direct drive targets performed in a very similar way. The direct drive $x$ rays, only $1 \%$ of the yield, were in both cases a $1.8-\mathrm{keV}$ blackbody spectrum. The direct drive yield was $19 \%$ debris energy with the remainder made up of neutrons. The low fraction of energy in $x$ rays is due to the fact most of the target is fully ionized at the end of the burn, so Bremsstrahlung is the dominant radiative emission process.

The indirect drive targets have a much larger fraction of their energy in $x$ rays because the debris energy coming out of the capsule is converted into $x$ rays by the collision between the capsule debris and the hohlraum case. The indirect drive $\mathrm{x}$-ray spectra are much cooler than the direct drive spectra because the stagnation region between the capsule and case is much cooler than the DT core during burn. A major difference between $\mathrm{x}$ rays emitted by direct and indirect NIF targets is the angular dependence. Direct drive $\mathrm{x}$ rays are isotropic. Indirect drive $\mathrm{x}$ rays, when viewing the target facing the laser entrance hole, are much more intense and have a harder spectrum than when viewing the hohlraum wall. Calculations of NIF target $\mathrm{x}$-ray and debris emission with the BUCKY 1-D code that describe this difference in detail are presented elsewhere. ${ }^{6}$

\section{FIRST WALL LASER LIGHT IRRADIATION}

Direct drive targets are fully subtended by the laser beam. As the target implodes, significant amounts of incident laser light can be refracted to the chamber wall (since the beam retains a fixed cross section), presenting the possibility of unacceptable material removal due to laser interaction with the wall. Predictions of the laser first wall irradiation using LASNEX were performed by Weber of LLNL. ${ }^{7}$ The direct drive target chosen for analysis had a radius of $1.695 \mathrm{~mm}$ and was irradiated with a $1.6-\mathrm{MJ}$ continuous laser pulse, with about $200 \mathrm{~kJ}$ in a foot pulse of $5.5 \mathrm{~ns}$ and the remainder in a 6-ns main pulse.

The calculation consisted of modeling a hemisphere of the target and irradiating it with half of the $1.6 \mathrm{MJ}$ of energy. Each beam was modeled as 50 individual rays uniformly distributed across the beam with each ray having equal energy, as shown in Fig. 2. As the capsule was compressed, LASNEX calculated the new power and angle of each ray as a function of the angle of incidence. The calculation used 50 equal bins to establish the angular distribution of the refracted rays over $\pi$ radians $\left(180^{\circ}\right)$. The peak fluence on the far wall for a single beamlet is $\sim 0.04 \mathrm{~J} / \mathrm{cm}^{2}$ at about $20^{\circ}$ from a $0^{\circ}$ angle of incidence. Integrating over the entire first wall for all 192 beams indicates the first wall laser fluence ranges from 0.18 to $0.25 \mathrm{~J} / \mathrm{cm}^{2}$. We have set $0.3 \mathrm{~J} / \mathrm{cm}^{2}$ as the bounding first wall UV laser irradiation threat.

\section{RESPONSE OF CHAMBER SURFACES TO DIRECT DRIVE TARGET EMISSIONS}

The vaporization and melting of the NIF target chamber first wall has been calculated with the BUCKY code. $^{8}$ Target $x$ rays and debris parameters from the BUCKY calculations presented in reference (6) are used as inputs for these calculations. Two sets of 1-D BUCKY calculations predict the $\mathrm{X}$-ray and debris emissions for indirect drive in two directions: out through the hohlraum case, labeled the Case Spectrum, and out through the laser entrance hole, labeled the Oblique Spectrum. This case includes the effects of capsule plasma stagnation against the case wall. There were three materials considered: B, $\mathrm{Al}_{2} \mathrm{O}_{3}$, and $\mathrm{SiO}_{2}$. Direct and indirect drive spectra were both considered. The NIF material response, as well as high-energy tritium ion deposition in the chamber walls, is discussed in more detail elsewhere. ${ }^{9}$ 
In these calculations, the BUCKY code deposits the $\mathrm{x}$-ray and debris energy in the material and then uses the local energy density to determine whether the material is vaporized or melted. Both forms of energy are deposited in a time-dependent manner, which competes with the conduction of heat away from the surface. This results in a steep temperature profile in the target chamber material. The material that is above the melting temperature is assumed melted. The heat of fusion is ignored. Material is evaporated from the surface of the material at a rate determined by the surface temperature and the lattice separation energy. The results are summarized in Table 3.

No melting or vaporization was seen for $\mathrm{B}$ or $\mathrm{Al}_{2} \mathrm{O}_{3}$ from the $\mathrm{x}$ rays from the case or the oblique radiation from a 20-MJ indirect drive target. The response of $\mathrm{SiO}_{2}$ to this radiation and debris has not been studied. A parametric study of the response of $\mathrm{B}$ and $\mathrm{Al}_{2} \mathrm{O}_{3}$ as a function of target yield has been performed. The results are given in Table 3. B experiences no vaporization or melting for either X-ray spectrum up to a target yield of at least $45 \mathrm{MJ}$, considered the maximum credible yield for NIF. $\mathrm{Al}_{2} \mathrm{O}_{3}$ is not damaged at either $100-\mathrm{kJ}$ or $20-\mathrm{MJ}$ yields for either spectrum, but is slightly melted at a 45-MJ yield. Therefore, these calculations show that $B$ is a marginally better first wall coating material from the point of view of $x$ ray vaporization by indirect drive NIF targets.

The debris spectra from indirect drive targets is not well characterized, but some information has been reported. ${ }^{10}$ Damage from indirect drive debris is very likely less severe than for direct drive targets for two reasons: the duration of the debris pulse that results from hohlraum disassembly is $\sim 1 \mu \mathrm{s}$, a long time compared to thermal conduction times, and the amount of energy in debris for equal yields is $\sim 2.5$ times more for direct drive.

The target debris from direct drive targets can damage in-chamber materials. The target $\mathrm{x}$-ray fluence is much lower than the debris fluence, and the $\mathrm{x}$-ray spectrum is hard enough that the deposition length is long in the chamber materials so the specific energy in the material is relatively low. Therefore, as it is appropriate to neglect the effects of $x$ rays, the melting and vaporization caused by the debris from a 40-MJ plastic-coated direct drive target has been calculated with BUCKY, using the debris spectrum discussed above. The results are summarized in Table 4. Here, $\mathrm{B}$ is clearly superior to $\mathrm{Al}_{2} \mathrm{O}_{3}$. Also the debris shield, which is made of $\mathrm{SiO}_{2}$, will be damaged by this direct drive target yield.
Table 3. Wall Damage from Indirect Drive Target $\mathrm{X}$ rays

\begin{tabular}{|c|c|c|c|c|c|c|}
\hline & \multicolumn{3}{|c|}{$\overline{\mathbf{B}}$} & \multicolumn{3}{|c|}{$\mathrm{Al}_{2} \mathrm{O}_{3}$} \\
\hline $\begin{array}{l}\text { Target Yield } \\
\text { (MJ) }\end{array}$ & 0.1 & 20 & 45 & 0.1 & 20 & 45 \\
\hline \multicolumn{7}{|c|}{ CASE SPECTRUM } \\
\hline $\begin{array}{l}\mathrm{X} \text {-ray Fluence } \\
\left(\mathrm{J} / \mathrm{cm}^{2}\right)\end{array}$ & 0.28 & 0.91 & 1.68 & 0.28 & $\overline{0.91}$ & 1.68 \\
\hline $\begin{array}{l}\text { Debris Fluence } \\
\left(\mathrm{J} / \mathrm{cm}^{2}\right)\end{array}$ & 0.29 & 0.94 & 1.75 & 0.29 & 0.94 & 1.75 \\
\hline $\begin{array}{l}\text { Vaporized Mass } \\
\left(\mathrm{mg} / \mathrm{cm}^{2}\right)\end{array}$ & 0 & 0 & 0 & 0 & $\overline{0}$ & 0.01 \\
\hline $\begin{array}{l}\text { Vaporized } \\
\text { Thickness }(\mu \mathrm{m})\end{array}$ & 0 & 0 & 0 & 0 & 0 & .025 \\
\hline $\begin{array}{l}\text { Melted Mass } \\
\left(\mathrm{mg} / \mathrm{cm}^{2}\right)\end{array}$ & 0 & 0 & 0 & 0 & 0 & 0.1 \\
\hline $\begin{array}{l}\text { Melted } \\
\text { Thickness }(\mu \mathrm{m})\end{array}$ & 0 & $\overline{0}$ & 0 & $\overline{0}$ & $\sqrt{0}$ & 0.25 \\
\hline \multicolumn{7}{|c|}{ OBLIQUE SPECTRUM } \\
\hline $\begin{array}{l}\text { X-ray Fluence } \\
(\mathrm{J} / \mathrm{cm} 2)\end{array}$ & 0.26 & .83 & 1.55 & 0.26 & 0.83 & 1.55 \\
\hline $\begin{array}{l}\text { Debris Fluence } \\
(\mathrm{J} / \mathrm{cm} 2)\end{array}$ & 0.32 & 1.02 & 1.89 & 0.32 & 1.02 & 1.89 \\
\hline $\begin{array}{l}\text { Vaporized Mass } \\
\left(\mathrm{mg} / \mathrm{cm}^{2}\right)\end{array}$ & 0 & 0 & 0 & 0 & 0 & 0 \\
\hline $\begin{array}{l}\text { Vaporized } \\
\text { Thickness }(\mu \mathrm{m})\end{array}$ & 0 & 0 & 0 & 0 & 0 & $\mathbf{0}$ \\
\hline $\begin{array}{l}\text { Melted Mass } \\
\left(\mathrm{mg} / \mathrm{cm}^{2}\right)\end{array}$ & 0 & 0 & 0 & 0 & 0 & .051 \\
\hline $\begin{array}{l}\text { Melted } \\
\text { Thickness }(\mu \mathrm{m})\end{array}$ & 0 & 0 & 0 & 0 & 0 & 0.13 \\
\hline
\end{tabular}

Table 4. Predicted First Wall Damage by 40-MJ Direct Drive Target Debris

\begin{tabular}{|l|l|l|l|}
\hline & $\mathbf{B}$ & $\mathbf{A l}_{2} \mathbf{O}_{3}$ & $\mathbf{S i O}_{2}$ \\
\hline Vaporized Mass $\left(\mathrm{mg} / \mathrm{cm}^{2}\right)$ & 0 & .0035 & 0.079 \\
\hline Vaporized Thickness $(\mu \mathrm{m})$ & 0 & 0.009 & 0.35 \\
\hline Melted Mass $\left(\mathrm{mg} / \mathrm{cm}^{2}\right)$ & 0 & 0.29 & 0.12 \\
\hline Melted Thickness $(\mu \mathrm{m})$ & 0 & 0.75 & 0.55 \\
\hline
\end{tabular}

\section{EFFECTS OF FIRST WALL LASER IRRADIATION}

Experiments have been conducted to examine the response of $\mathrm{B}_{4} \mathrm{C}$ to laser light irradiation. ${ }^{11}$ For $350-\mathrm{nm}$ laser light irradiation of $2.4 \mathrm{~ns}$, the threshold for significant $\mathrm{B}_{4} \mathrm{C}$ surface melting is between 0.5 and 
$1 \mathrm{~J} / \mathrm{cm}^{2}$. Higher fluences appear to induce thermal crazing of the surface in a pattern similar to that observed for $x$ rays. The damage fluence threshold varies with pulse length. Thermal conduction and two-photon effects predict a t ${ }^{0.5}$ dependence, but observed dependence is weaker. The primary mechanism for material removal at $\leq 1 \mathrm{~J} / \mathrm{cm}^{2}$ appears to be particulate spallation. Most of the spalled particles are $<5 \mu \mathrm{m}$. The onset of vaporization is

$\sim 1.5 \mathrm{~J} / \mathrm{cm}^{2}$. This is expected to result in a thin absorbing film on the NIF final optics and must therefore be avoided.

Laser light is attenuated exponentially as it is absorbed in the material, as long as the intensity is below a threshold for plasma formation at the target surface. The linear absorption coefficient decreases roughly exponentially with wavelength from 31 to $3.9 \mu^{-1}$ over the range of 350 to $1050 \mathrm{~nm}$. That the observed damage threshold is several times higher for $1.053-\mu \mathrm{m}$ light than $0.35-\mu \mathrm{m}$ light is consistent with the smaller absorption coefficient.

Results suggest the predicted NIF first wall $3 \omega$ fluence for the direct drive scenario is half the spall fluence and one-fourth the vaporization fluence. These results suggest a diffraction grating that distributes unconverted NIF laser light uniformly to the first wall $\left(0.7 \mathrm{~J} / \mathrm{cm}^{2}\right.$ of 1,2 , and $3 \omega$ ), would be a superior solution to the wedged focus lens/absorbing glass first wall solution currently proposed, in that the fused silica 'beam dump' cover, which undergoes vaporization and damage at yields below $20 \mathrm{MJ}$, would no longer be needed. Such a grating appears feasible to develop. ${ }^{13}$

\section{CONCLUSIONS}

The NIF will be designed to 'not preclude' implementing direct drive ICF. The required re-positioning of beams would be accomplished by engaging preemplaced added transport mirrors in the target area bay. The increased beam path difference is compensated by modifications to the laser front end. The final optics assemblies would be modified through removal and rebuilding of the Integrated Optics Modules to incorporate the frequency conversion and smoothing by spectral dispersion required by direct drive. Unconverted light management for direct drive is accomplished by unconverted light absorbers moved to the required new locations, or implementation of a grating that disperses the unconverted light. Development of absorbers that can withstand higher frequency modulation may be necessary.

Direct drive targets contain five times more tritium than indirect drive targets presenting constraints on their use compared to indirect drive due to NIF tritium inventory and throughput limits. $\mathrm{X}$-ray emissions from direct drive targets appear to be far less damaging than for indirect drive and do not present a threat to the NIF first wall. The debris emissions, on the other hand, at the maximum 20-MJ yield, appear to cause damage to fused silica beam dumps and possibly debris shields and is an area that would require further investigation. The first wall laser irradiation possible from direct drive shots can be withstood by $\mathrm{B}_{4} \mathrm{C}$ at the 5-m chamber radius.

The authors wish to acknowledge the support of M. Cray and LANL for the LASNEX calculations of direct drive targets. This work was performed under the auspices of the U.S. Department of Energy by Lawrence Livermore National Laboratory under contract No. W-7405-Eng-48.

\section{REFERENCES}

1. D. Eimerl (Ed.), Configuring the National Ignition Facility for Direct Drive Experiments, Lawrence Livermore National Laboratory, Livermore, California, UCRL-ID-120758 (July 1995).

2. NIF Baseline Review, Lawrence Livermore National Laboratory, Livermore, California, NIF-LLNL-95421, L-20078-01 (July 26-27, 1995).

3. NIF Draft Preliminary Safety Analysis Report, Lawrence Livermore National Laboratory, Livermore, California, UCRL-ID-123759 DR (1996).

4. A. Anderson and P. Peterson, X-ray Emission from National Ignition Facility Indirect Drive Targets, Lawrence Livermore National Laboratory, Livermore, California, UCRL-JC-123557 (1996).

5. C. Fontes, Los Alamos National Laboratory, private communication.

6. R.R. Peterson, J.J. MacFarlane, and P. Wang, "X-ray and Debris Emission from Direct and Indirect National Ignition Facility Targets," these proceedings.

7. M. Tobin and S. Weber, "Threat to the NIF First Wall Due to Unabsorbed $3 \omega$ Light Using Direct Drive," Lawrence Livermore National Laboratory, Livermore, California, Internal Memo TAT 96-017.2 (1996).

8. J.J. MacFarlane, G.A. Moses, and R.R. Peterson, BUCKY-1-A I-D Radiation Transport Code for Simulating Inertial Confinement Fusion High Energy Density Plasmas, University of Wisconsin, Madison, Wisconsin, Fusion Technology Institute Report UWFDM-984 (August 1995).

9. R.R. Peterson, "Response of National Ignition Facility First Wall Materials to Target X rays and Debris," these proceedings.

10. M. Garaseminko 
11. M. Tobin, A. Anderson, A. Burnham, and T. Bernat, Assessment of First Wall Damage from Target X-ray Emission and Scattered Laser Light for the National Ignition Facility, Lawrence Livermore National Laboratory, Livermore, California, UCRL-JC-?? (1996).

13. M. Perry, Lawrence Livermore National Laboratory, private conversation. 

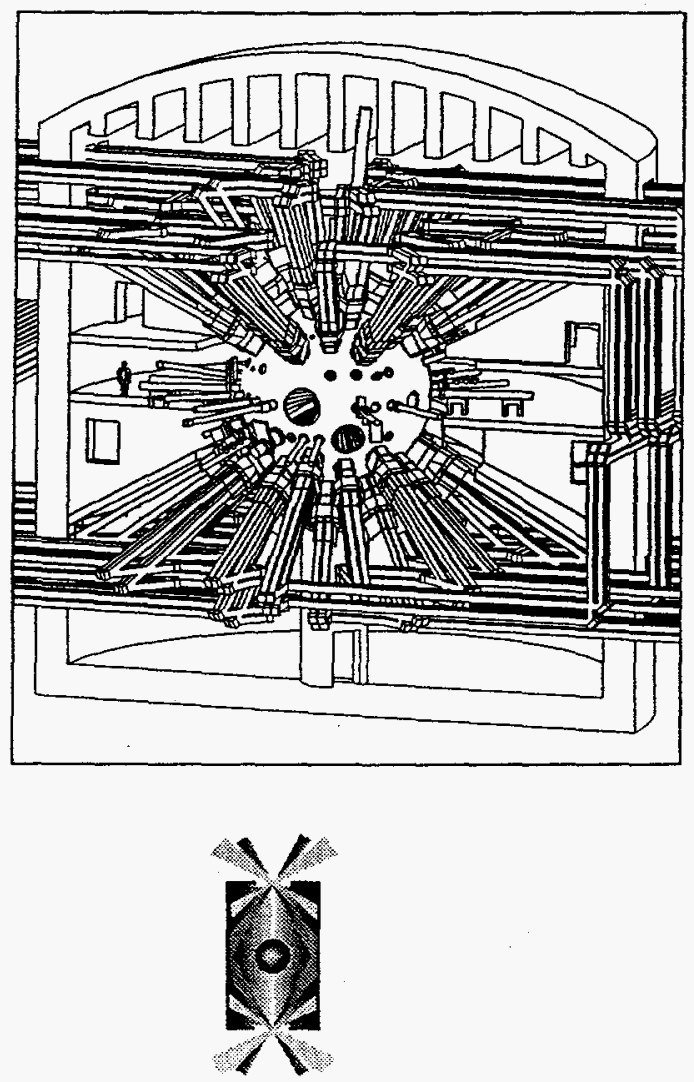

Laser target indirect drive
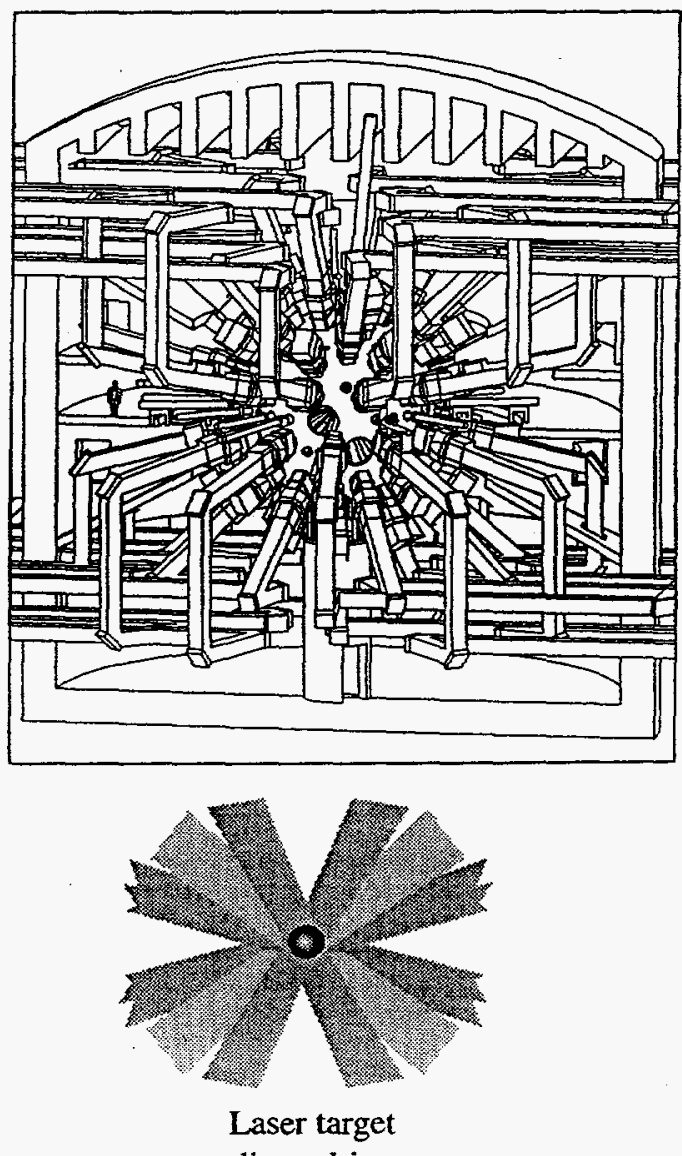

direct drive

Fig. 1. The NIF indirect-drive system is designed to accommodate direct drive through the use of additional transport mirrors ( 96 in all) to redirect 24 four-beam clusters to the chamber 'waist'. 


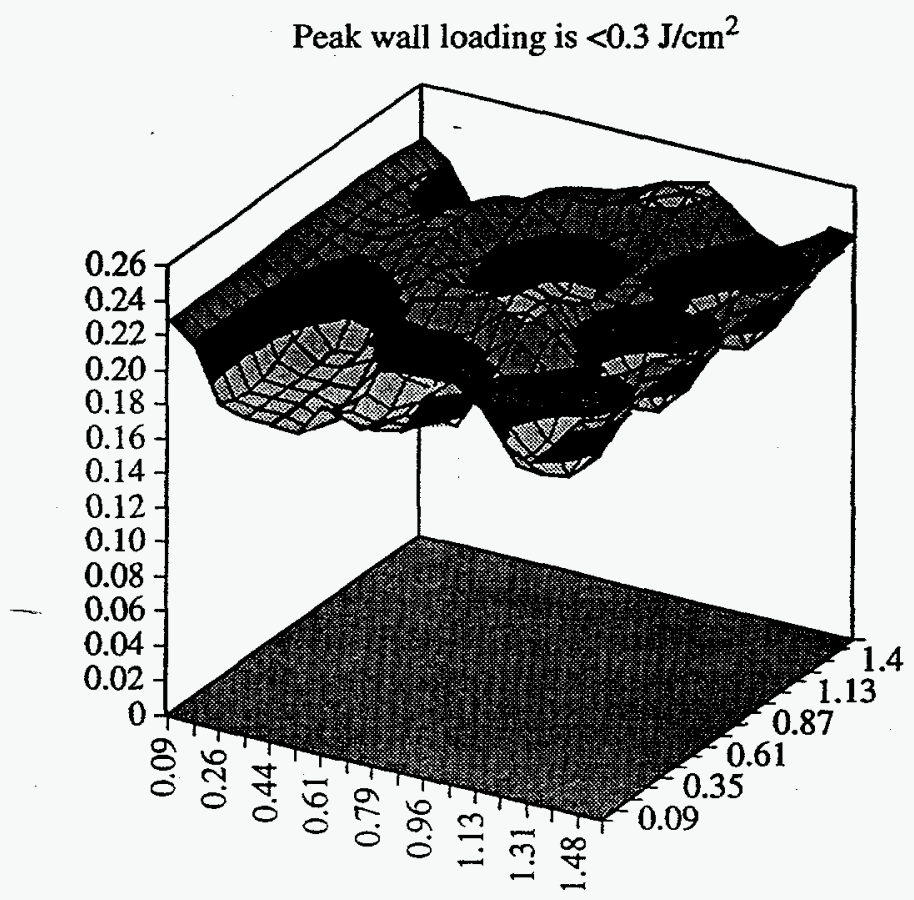

LASNEX calculation predicts $\sim 4$ ns, $40 \%$ scatter of incident $3 \omega$ light

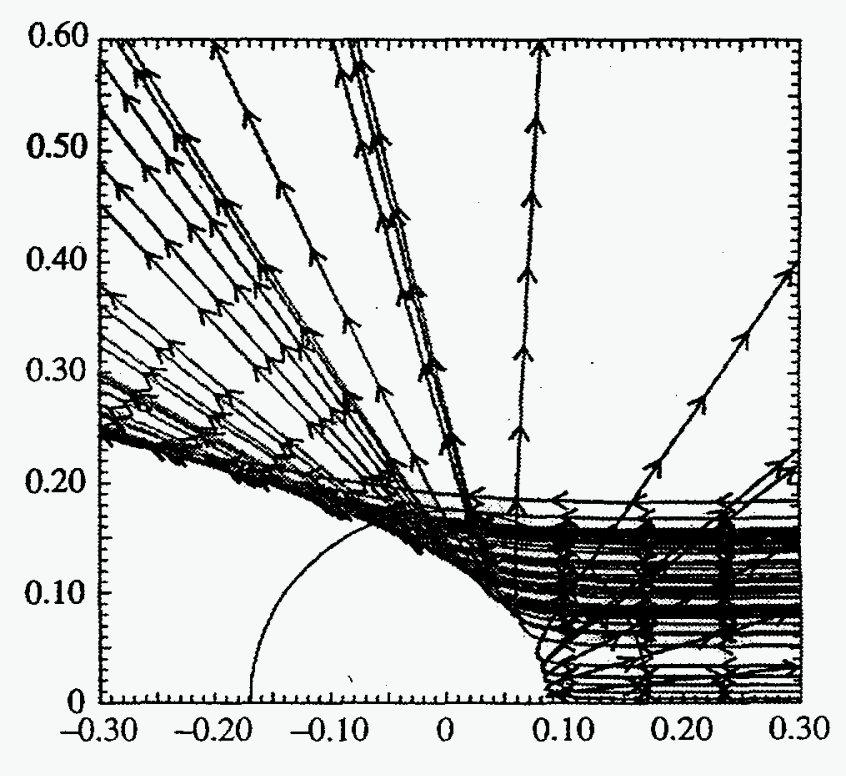

Fig. 2. NIF, operating in a direct-drive mode, will create a laser irradiation threat to the first wall. The capsule implosion for fixed beam spot size results in a significant $3 \omega$ fluence on first wall due to plasma interactions and a shrinking target.

40-00-0596-1223pb01 